\title{
Eğitim Yönetiminde Teknoloji Kullanımına İlişkin Okul Yöneticilerinin Görüşleri ${ }^{1}$
}

\author{
DOI: $10.26466 /$ opus.652611
}

\author{
İhsan Topcu * - Mustafa Ersoy** \\ * Dr. Öğrt. Üyesi, Sivas Cumhuriyet Üniversitesi, Eğitim Fakültesi \\ E-Posta: ihsantopcu@cumhuriyet.edu.tr \\ ORCID: 0000-0002-6712-3238 \\ ** Dr. Öğrt. Üyesi, Sivas Cumhuriyet Üniversitesi, Eğitim Fakültesi \\ E-Posta ersoy.mustafa@gmail.com \\ ORCID: $\underline{0000-0002-7320-8844}$
}

\section{Öz}

Örgütlerin kendilerini yenilemeleri ve geliştirebilmeleri için en önemli rol yöneticilerine düşmektedir. Bu aynı zamanda okul yöneticileri için de geçerlidir. Günümüzde gelişme ve değişsim yaşamın her alanında kaçınılmazdır ve tüm kuruluşlar gibi, eğitim kuruluşları da internet ve bilgisayar gibi en yüksek teknolojiden faydalanmak zorundadır. Telekomünikasyon alanındaki bilgisayarlar, teknolojiler ve diğer gelişmeler ülkemizde gerçekleştirilecek olan eğitim reformları için kilit faktörlerden biri olabilir. Teknolojinin okulların yeniden yapılandırılmasında önemli bir rol oynayacă̆ına inanilmaktadır. Bu nedenle, yönetimde teknolojiden yaralanmayı bilen ve bunu yönetimsel süreçlere uygulayabilen okul müdürleri daha etkili okullar oluşturmak için daha ayrıcalıklı olacaktır. Bu çalışma, okul müdürlerinin eğitim kurumlarında etkili okul yönetimi için teknoloji kullanımı hakkındaki görüşlerini ortaya koymayı amaçlamaktadır. Günümüzde sosyal bilimlerde nitel araştırmaların yoğunluğu giderek artmaktadır Çalışmada nitel araştırma yöntemi kullanılması tercih edilmiştir. Okul yöneticilerinin duygu, düşünce ve bilgileri derinlemesine açı̆̆a çıkarabilmek için olgubilim deseni tercih edilmiştir. Araştırmanın katılımcıları amaçlı örnekleme yoluyla belirlenmiştir. Katılımolar Sivas il merkezindeki özel ve devlet okullarında görev yapan yedisi okul müdür, yedisi müdür yardımcısı olmak üzere toplam 14 okul yöneticisinden oluşmaktadır. Araştırmanın verileri araştırmacılar tarafından geliştirilirmiş olan yarı yapılandırılmış görüşme formlarıyla toplanmıştır. Araştırmanın verileri içerik analizi yapılarak analiz edilmiştir. Araştırmaya katılan yöneticilerin teknolojiye ve teknolojinin yönetimde kullanılmasına olumlu baktıkları anlaşılmıştır. Araştırmada okul yöneticilerinin teknolojik yeterlilikleri, teknolojiyi yönetimde kullanma konusunda katılımcılara göre farklı sonuçlar elde edilmiştir. Araştırmada okul yöneticilerinin teknolojiyi daha çok öğrenci hizmetleri, personel hizmetleri, büro işleri gibi rutin ama kolaylaştırıcı ve zaman kazandırıcı işler için kullandıkları bulgusuna varılmıştır. Teknolojiyi yönetim süreçlerinde kullanma bakımından değerlendirildiğinde, çalışmaya katılan yöneticilerin teknolojiyi etkin kullanamadıkları sonucuna ulaşılmıştır.

Anahtar Kelimeler: Okul yönetimi, Etkili yönetim, Yönetimde teknoloji, Teknolojik yeterlilik, Ĕ̆itimde teknoloji kullanımı

\footnotetext{
${ }^{1}$ Bu çalışma 27-28 Ekim 2017 tarihlerinde Sivas'ta düzenlenen 1.International Educational Technology Sympoium'da sunulan bildirinin genişletilmiş halidir
} 


\title{
School Administrators' Opinions on the Use of Technology in Educational Administration
}

\begin{abstract}
The most important role for organizations to renew and improve themselves falls to their managers. This also applies to school administrators. Today, development and change are inevitable in all aspects of life and, like all organizations, educational institutions must make use of the highest technology, such as the Internet and computers. Computers, technologies and other developments in the field of telecommunications can be one of the key factors for the educational reforms to be undertaken in our country. It is believed that technology will play an important role in the restructuring of schools. Therefore, school principals who know how to exploit technology in management and apply it to managerial processes will be more privileged to create more effective schools. This study aims to reveal the views of school principals about the use of technology for effective school management in educational institutions. Nowadays, the intensity of qualitative research in social sciences is increasing gradually. In this study, it has been preferred to use qualitative research method, as well. Phenomenology design was preferred in order to reveal the emotions, thoughts and knowledge of the school administrators in depth. Participants of the study were determined by purposeful sampling. The participants consist of 14 school administrators, seven of whom are school principals and seven of them are assistant principals working in private and public schools in Sivas city center. The data of the study were collected by semistructured interview forms developed by the researchers. The data of the research was analyzed by content analysis. It was understood that the participants had positive views on technology and the use of technology in management. In the research, different results were obtained in terms of technological competencies of school administrators and using technology in management. In the study, it was found that school administrators mostly use technology for routine but facilitating and time-saving tasks such as student services, personnel services and office work. When evaluated in terms of using technology in managerial processes, it was concluded that the managers participating in the study could not use the technology effectively.
\end{abstract}

Keywords: School administration, Technology leadership, Effective school management, Technology in school management, Technological competence 


\section{Giriş}

İnsanlık uygarlık yolunda uzun bir geçmişe ve birikime sahiptir. Yaşanan her yeni bir gün insanlığın birikimine çok daha fazla yeni şeyler katmaktadır. Günümüzde görülen en önemli gelişme ve katkı bilimsel gelişmelerde, bilgi birikiminde ve buna bağlı olarak teknoloji alanına olduğu da açıktır. Sanayi 4.0 aşamasına geçilmesiyle birlikte insan makine etkileşimi daha çok yaygınlaşmakta ve teknolojinin her alanda etkili kullanımı önem kazanmaktadır. Teknolojideki bu hızlı gelişmeler yaşamın her alanında insanların işlerini kolaylaştırmakta olduğu aşikârdır.

Teknoloji kavramının kullanıldığı yer ve durumlara göre farklı anlamlara geldiği ve tanımların da buna göre yapıldığı görülmektedir. Hoban (1965) teknolojiyi, "yönetim, süreç, düşünce, makine ve insan organizasyonlarının entegre olduğu karmaşık bir yapı" olarak tanımlamıştır (akt. İşman, 2014, s.1). Finn'in (1960), teknolojiyle ilgili tanımı ise şöyledir: "Makine kullanımının yanı sıra teknoloji, sistemler, işlemler, yönetim ve kontrol mekanizmalaryyla hem insandan hem de eşyadan kaynaklanan sorunlara, bu sorunların zorluk derecesine, teknik çözüm olasılıklarına ve ekonomik değerlerine uygun çözüm üretebilmek için bir bakış açısıdır" (akt. Alpar, Batdal ve Avcı, 2007, 22). İşman (2014, s.2), teknoloji ile ilgili yapılmış olan farklı tanımları şöyle özetlemektedir:"(1) teknik bir dil, (2) a: uygulamalı bilim, b: pratik bir amacı gerçekleştirmek için kullanılan teknik bir yöntem, (3) insanoğlunun rahatını sağlayan bütün gelişmelerin genel anlamı, (4) bir sanayi dalı ile ilgili yapım yöntemleri, kullanılan araç-gereç ve aygıtları kapsayan bilgi, uygulama bilimi, (5) belli bir teknik alanda bilimsel ilkelere dayanan tutarlı bilgi ve uygulamaların tümü, (6) tekniklere ilişkin genel kavram, ve (7) en yeni bilimsel buluş ve uygulamaların kullanıldığı donanım olanakları ve yapısal düzenlemeler".

Hangi tanım ele alınırsa alınsın teknoloji, "ekonomik, sosyal, siyasal, endüstri ve eğitim alanlarında ciddi değişikliklerin meydana gelmesini sağlayan önemli bir araç ve yöntemdir" (Bostancı, 2010, s.28). Geçerli ve etkili bir araç olarak teknolojinin eğitim yönetiminde kullanılması kaçınılmaz bir durumdur. Yönetim amaca giden yolda birtakım süreçlerin yürütülmesi olarak kabul edilirse, bu süreçlerin verimli, etkili ve rasyonel bir şekilde yürütülmesinde teknoloji kullanımına ihtiyaç vardır. Golden (2004)'a göre “Teknoloji, 
her seviyeden eğitim liderlerine güç verme ve 21. yüzyılda eğitimin ne anlama geldiğini yeniden tanımlama potansiyeline sahip bir araçtır. Teknoloji, daha doğru bilgi ve gelişmiş iletişim olanakları sağlar. Teknoloji, yönetim ve işletim sistemlerini iyileştirmek ve kanıtlanmış öğretim yöntemlerini belirlemek için kullanılabilir" (akt. Durnalı, 2018, s.23).

Eğitim teknolojisi, başka bir ifadeyle, eğitimde teknoloji kullanılması ile eğitim yönetiminde teknoloji kullanılması ayrı kavramlar olarak ele alınmalıdır. "Eğitim teknolojisi geniş anlamıyla, öğretme ve öğrenmeyi teşvik etmek, kolaylaştırmak ve öğrenciyi güdülemek amacını güden araç-gereçler ile belirli öğretme-öğrenme sistemleriyle ilgili süreçleri, tasarımları ve yöntemleri kapsar" (Bostanc1, 2010, s.9). Eğitim teknolojisi daha çok öğretimsel etkinliklerde teknolojinin etkin kullanımını kapsar. Eğitim yönetiminde teknoloji kullanımının odağında ise eğitimle ilgili planlama, tasarım ve değerlendirilmeler ve bunlara ilişkin daha doğru, etkili kararların alınması ve yönetime ilişkin süreçlerin daha rasyonel sürdürülmesi yer alır. Eğitimde teknolojik liderlik her iki boyutu kapsayan ve eğitim örgütlerinde hem öğretimsel etkinliklerde hem de yönetimsel uygulamalarda teknolojiden etkin yararlanmayı gerektirir.

Yönetimde teknoloji kullanımı genel olarak örgütsel düzeyde yönetimle ilgili süreçlerin ve faaliyetleri planlamak, hedefleri belirlemek ve bu hedeflere etkili bir şekilde ulaşabilmek için uygulamalı bilimlerden, teknolojik araç ve gereçlerden yararlanılması durumu olarak tanımlanabilir. Yönetimde teknoloji kullanımı aslında yeni bir uygulama değildir. Özellikle bilgisayarların birçok alanda kullanılmaya başlanması ile eğitim alanında ve yönetsel işlerin daha etkili yürütülmesinde teknoloji kullanımı bir zorunluluk haline gelmiştir. Eğitim örgütlerinde bilgisayar kullanımı aşamalarını Özden (2003), aşağıdaki gibi sıralamaktadır:

- $\quad$ 1950'li yıllarda bilgisayarlar büyük üniversitelerin yönetimsel amaçlı kullanımları ile eğitim kurumlarına girmiştir.

- 1960'larda bilgisayar temelli öğretim programlarının geliştirilmesi çalışmaları başlatılmıştır. Bu projelerden birisi de PLATO'dur.

- 1970'li yıllarda daha fazla sayıda okul bilgisayarları idari amaçlı olarak kullanmaya başlamıştır.

- 1972 yılında TICCIT (Zaman Paylaşımlı ve Etkileşimli Bilgisayar Kontrollü Öğretici Televizyon) sistemi geliştirilmeye başlanmıştır. 
- 1970lerden sonra internetin gelişimi ile kişisel bilgisayardan, ağ sistemlerine ve internete doğru bir yönelim başlamıştır.

- Türkiye'nin de 1993 yılında dahil olduğu internet omurgası NFSNET ağ omurgasına ülkelerin hızla katılması ve çok hızlı artan ve bir teknoloji yarışının başlaması ile yeni bir döneme girilmiştir.

Günümüzde teknolojinin çok yönlü ve etkili olarak okullarda kullanılması yönetimsel etkililiğin sağlanmasında zorunlu bir araç olarak görülmektedir. Okulun stratejik planlaması için gerekli süreçlerin yürütülmesinden öğrencilerle ilgili verilerin sisteme girilmesi ve korunmasına, velilerle iletişimden her türlü etkinliğin kolayca ve kısa zamanda planlamasına kadar geniş bir alanda teknoloji kullanımı yönetime kolaylıklar sağlamaktadır.

Eğitim yönetiminde teknoloji kullanımında en önemli görev ve sorumluluk okulun yöneticilerine düşmektedir. Bu nedenle okul yöneticilerinin teknolojik liderlikleri ve teknoloji konusundaki yeterliklerine ilişkin çalışmalar yapıldı̆̆ı görülmektedir (Flanaganand Jacobsen, 2003; Seay, 2004; Erbakırc1, 2008; Bostancı, 2010; Banoğlu, 2011; Çalık, Çoban ve Özdemir, 2019). Alanyazında yapılan çalışmaları gözden geçiren Turan (2002)'ın aktardığına göre eğitim yöneticilerinin teknolojiyi kullanabilme konusundaki yeterlilikleri aşağıdaki gibi özetlenmiştir:

- Bilgisayar ve teknoloji ile ilgili temel kavramları anlama,

- Belli başlı yazılımları ve donanım yazılımlarını tanımlayabilme,

- Yazılım ve donanım seçiminde ve değerlendirilmesinde göz önünde bulundurulması gereken özellikleri bilebilme,

- Teknolojinin okulda ve eğitim sisteminde kullanılmasına ilişkin vizyon geliştirebilme,

- Teknoloji alımı için kaynak arama,

- Teknolojiyle ilgili kullanım önceliklerini ve alanların belirleme,

Günümüzde bu yeterlikler yenileriyle birlikte geçerliliğini korumaktadır. Okulların daha etkili yönetilmesinde ve verimliliğin artırılmasında, denetimin daha etkin yapılmasında, şeffaflı̆̆ın ve hesap verilebilirliğin sağlanmasında teknoloji kullanımında daha fazla ihtiyaç duyulmaktadır.

Bilindiği gibi, milli eğitim bakanlığı "Mutlu çocuklar güçlü Türkiye” sloganıyla eğitimde 2023 Vizyon Belgesini 2019 yılında kamuoyuna açıklamıştır ve bu doğrultuda çalışmalara hız verdiğini duyurmuştur. Bu vizyon belgesinin temelini oluşturan asıl dayanak ise MEB 2019-2023 stratejik planıdır 
(MEB, 2018). Bu plan çerçevesinde belirlenmiş olan hedefler vizyon belgesine yansitılmıştır.

$\mathrm{Bu}$ vizyon belgesini ilgili taraflara tanitmak ve uygulamada daha etkin hale getirmek amaciyla ülke genelinde birçok etkinlikler düzenlendi ve düzenlenmeye de devam ediyor. Örneğin tüm iller ve ilçelerde gerek il, ilçe eğitim müdürlükleri gerekse okullar düzeyinde toplantılar ve çalıştaylar yapıldı. 2023 vizyon belgesinde en çok kullanılan kavramların arasında bilim, yönetim ve teknoloji geldiği görülmektedir (MEB, 2019). Vizyon belgesinde vurgulana önemli hususlardan birisi de eğitimin tüm alanlarında teknolojinin daha etkili bir şekilde kullanılmasına öncelik verilmesi ve veriye dayalı yönetimin öne çıkarılmasıdır. 2023 Vizyon belgesinde "Ülke genelinde yönetim ve öğrenme etkinliklerinin izlenmesi, değerlendirilmesi ve geliştirilmesi için okul bazında Veriye Dayalı Planlama ve Yönetim Sistemine geçilecektir" (MEB, 2019, 28) ifadesi yer almaktadır. Veriye dayalı yönetim ile daha rasyonel değerlendirmeler ve analizler yapılabileceği ve daha doğru kararlarla etkili bir yönetimin sağlanacağı vurgulanan belgede şöyle devam etmektedir (MEB, 2019, s.29):

Ülke ölçeğinde eğitimin baştan sona să̆̆lklı bir şekilde yönetilebilmesi amacıyla hem geçmiş kararlara yönelik objektif değerlendirmeler hem de geleceğe yönelik gerçekçi planlar yapılacaktır. Bunun için de çeşitli ve büyük miktarda verinin işlenerek birbirleriyle ilişkilendirilmesi, sürekli değişen koşullara göre yapılandırlması ve sebep sonuç ilişkisi açısından anlamlandırlması gerekmektedir. Ortaya çıkan büyük verinin, kurulacak "Öğrenme Analitiği Platformu"nda analiz edilecektir. Böylece okul performanslarından öğretmenlerin mesleki gelişim ihtiyaçlarmın belirlenmesine, müfredatm etkinliğinin ölçülmesinden fiziki kapasite ve personel ihtiyaçlarmın analizine ve hatta öğrencilerin bireysel performanslarma yönelik kararlar verilebilmesine kadar tüm süreçlerin değerlendirilmesi ve gerekli aksiyonları zamanında alınması mümkün olacaktır. Aynı zamanda Öğrenme Analitiği Platformu'ndaki araçlarla; öğrenci gruplarmm performansları ve okulların katma değerleri hakkında açıklayıcı, tahmine yönelik ve tavsiye niteliğinde analiz ve simülasyonlar yaplabilecek böylece olası kararların yol açabileceği risklerin anlaşılması sağlanacaktır. 
Böylece bakanlık eğitim yönetiminde alınacak kararlara yönelik daha objektif değerlendirmeler yapılabileceğini, planlamanın daha gerçekçi yürütülebileceğini ve böylece eğitim sisteminin baştan sona daha sağlıklı yönetileceğini ifade etmektedir. Bakanlık bünyesinde ve alt sistemlerinde toplanan çok büyük veriler daha rasyonel ve sağllklı olarak analiz edilebilecektir. Okulların performansları, öğretmenlerin gelişim ihtiyaçları, kullanılan müfredatın etkililiği, öğrencilerin bireysel performansları bu yolla daha iyi belirlenebilecek, bunlara ilişkin simülasyonlar yapılıp daha doğru kararlar alınabilecektir. "Tüm bu veriye dayalı yönetim anlayışı çerçevesinde iyileştirilecek süreçler aracllı̆̆ıyla öğretmen, okul yöneticisi ve eğitim yöneticilerimizin üzerindeki bürokratik iş yükü azaltılacaktır. Böylece odağında çocuğun öğrenmesinin birincil amaç olduğu öğrenme ve yönetim sistemi tesis edilecektir" (MEB, 2019, s.29).

$\mathrm{Bu}$ aktarımlardan da anlaşılacağı üzere, bakanlık eğitimin yönetiminde teknoloji kullanımını yaygınlaştırmayı ve daha etkin hale getirmeyi hedeflemektedir. Bu hedefin gerçekleştirilmesi birçok etkene bağlı olmakla birlikte en önemlisi okul yöneticilerinin teknolojik liderliğe ilişkin yeterlikleri ve eğitimde teknoloji kullanımına ilişkin tutum ve davranışlarıdır. Bu iki etkenden okul yöneticilerinin teknoloji liderliği son yıllarda birçok araştırmaya konu olmuş ve belirli düzeyde literatür oluşmuş gözükmektedir (Turan, 2002; Karsl1, 2002; Erbakırc1, 2008; Afshari, et.al, 2009; Banoğlu, 2011; Yıldız ve İşcan, 2013; Sincar ve Aslan 2011; Berber, 2017; Sayracı ve Gündüz, 2018). Eğitim yönetiminde teknoloji kullanımına ilişkin bazı çalışmalar yapılmış olmakla birlikte eğitim yönetiminde teknoloji kullanımına ilişkin yönetici ve öğretmen görüşleriyle ilgili çalışma yoktur.

Bu çalışma alanyazında görülen bu boşluğu doldurmaya yönelik bir katkı sağlamayı amaçlamıştır. Okul yöneticileri kendi görev ve sorumlulukları kapsamında teknolojiye nasıl baktıkları önemlidir. Okul yönetiminde teknoloji kullanılmasına ilişkin okul yöneticilerinin görüşlerinin bilimsel araştırmalarla ortaya konulması bu bakımdan önemlidir. Araştırmanın temel problemi çerçevesinde aşağıdaki sorulara yanıt aranmıştır.

1- Eğitim yönetiminde teknoloji kullanımına ilişkin yöneticilerin tutumları nasıldır?

2- Yöneticilerin (kendi algılarına göre) teknolojik yeterlik düzeyleri nedir? 
3- Okul yöneticileri yönetimde hangi alanlarda teknolojiyi etkin kullanabiliyorlar?

4- Eğitim yönetiminde teknolojiyi daha etkin kullanımı için neler yapılmalı?

\section{Yöntem}

Çalışmada nitel araştırma yöntemi kullanılması tercih edilmiştir. Bilindiği gibi sosyal bilimlerde nitel araştırmaların yoğunluğu giderek artmaktadır (Kocabıyık, 2016, s.55). Bunun nedenleri nitel araştırmalar konusunda temel eserler ortaya koymuş araştırmacilar tarafından ayrıntılı olarak yapılmıştır (Bogdan ve Biklen, 2006; Meriam, 2009; Creswell, 2012; Patton, 2015; Hai-Jew, 2015; Yin, 2016; Creswell, 2016). Özet bir cümleyle ifade etmek gerekirse sosyal olayları ve insan doğasına ilişkin olguları anlamada ve anlamlandırmada nitel araştırmaların önemli bir gücü olmasıdır. Bu gerçekliğe dayalı olarak son yıllarda nitel araştırmalarla ilgili yeni yöntem kitapları yayınlanmakta olduğu görülüyor (Chandra ve Shang, 2019; Costa, et al., 2019).

Bu çalışma nitel araştırmalarda çokça kullanılan olgubilim deseniyle yapılmıştır. Bu çalışma okul yöneticilerinin yönetimde teknoloji kullanımına ilişkin görüşlerini onların gözlemleri, deneyimleri ve algılarıyla ortaya koymayı amaçlamıştır. Bu olguyla ilgili duygu, düşünce ve bilgileri derinlemesine açığa çıkarabilmek için olgubilim deseni tercih edilmiştir. Olgubilim, olayın içinde bulunan ve olguları birebir yaşayan insanların deneyimlerini derinlemesine anlamamıza yardımcı olan bir araştırma desenidir (BowdenandWalsh, 2000; Starksand Trinidad, 2007; Flick, 2009; Lapan, et al., 2012; Tracy, 2013; Yin, 2016).

\section{Çalışma Grubu}

Olgubilim araştırmalarında katılımcılar çoğunlukla amaçlı örnekleme tekniğiyle belirlenmektedir. Bu araştırmanın katılımcıları da amaçlı örnekleme yoluyla belirlenmiştir. Amaçlı örneklem türlerinden birisi olan ölçüt örnekleme göre katılımcılar belirlenmiştir. Ölçütlerden birisi eşit sayıda müdür ve müdür yardımcısının belirlenmesidir. Diğer önemli bir ölçüt ise farklı branşlardan ve farklı hizmet süresine sahip katılımcıların seçilmiş olmasıdır. Katılımcılar Sivas il merkezindeki özel ve devlet okullarında görev yapan yedisi okul 
müdür, yedisi müdür yardımcısı olmak üzere toplam 14 okul yöneticisinden oluşmaktadır. Araştırmada katılımcı okul müdürleri Y1, Y2, ...Y7 olarak, müdür yardımcıları ise Yrd1 ... Yrd7 olarak kodlanmıştır. Katılımcıların demografik bilgileri Tablo 1'de verilmiştir.

Tablo 1.Katılımcılarnn Demografik Özellikleri

\begin{tabular}{lllll}
\hline Görevi & Cinsiyet & Öğrenim & Branşınız & Kidem \\
\hline Y1 & Erkek & Lisans & Türkçe & 7 \\
Y2 & Erkek & Lisans & Sinf & 23 \\
Y3 & Erkek & Lisans & Din Bil & 13 \\
Y 4 & Erkek & Lisans & Matematik & 22 \\
Y5 & Erkek & Lisansüstü & Fen Bilgisi & 17 \\
Y6 & Erkek & Lisans & Sinıf & 19 \\
Y 7 & Kadın & Lisans & Din Bilgisi & 5 \\
Yrd 1 & Erkek & Lisans & Sinuf & 22 \\
Yrd 2 & Erkek & Lisansüstü & İnilizce & 10 \\
Yrd 3 & Kadın & Lisans & Fen Bilgisi & 24 \\
Yrd 4 & Erkek & Lisans & Din Bilgisi & 29 \\
Yrd 5 & Erkek & Lisans & Matematik & 17 \\
Yrd 6 & Kadın & Lisans & Türkçe & 16 \\
Yrd 7 & Erkek & Lisans & Fen Bil. & 21 \\
\hline
\end{tabular}

Katılımcların en az beş yıl mesleki kıdeme sahip oldukları görülmektedir. 14 okul yöneticisi arasında üç kadın katılımcı bulunmaktadır. Katılımcılardan sadece ikisinin lisansüstü eğitim aldığı anlaşılmaktadır. Katılımcıların altısı 20 yıl üzerinde hizmet yapmış olup, diğer katılımcların hizmet yılı beş yıl ile 20 yıl arasında değişmektedir. Katılımcıların üçü kadın yönetici olup diğerleri erkek yöneticilerdir.

\section{Araştırma Verilerinin Toplanması ve Analizi}

Araştırmanın verileri araştırmacılar tarafından geliştirilirmiş olan yarı yapılandırılmış görüşme formlarıyla toplanmıştır. Görüşme formunda yer alan soruların anlaşılır ve açık olup olmadığı konusunda Türkçe konusunda uzman bir akademisyenin görüşlerinden yararlanılmıştır. Görüşme formunun kapsamı ve amaca uygunluğunu teyit etmek için eğitim bilimlerinde uzman iki kişinin (Eğitim Yönetiminde bir Dr. Öğr. Üyesi ve bir Doçent.) görüşüne başvurulmuştur. Yarı yapılandırılmış görüşme formunda beş ana ve üç sonda soru yer almaktadır. Görüşme formunun uygunluğunu test etmek için 
araştırmacılar tarafından ön uygulama yapılmış ve forma son şekli verilmiştir. Araştırmanın verileri Mayıs 2018 de yüz yüze görüşmeler yoluyla toplanmış ve görüşmeler ortalama yarım saat sürmüştür. Araştırmadan toplanan veriler içerik analizi yapılarak analiz edilmiştir. Görüşme metinleri ve araştırmacı notlarından elde edilen bulgular tablolar haline getirilmiş ve yorumlanmiştır.

\section{Araştırmanın Güvenirlik ve Geçerliliği}

Nitel araştırmalarda güvenirlik ve geçerliği sağlamanın koşulları nicel araştırmalardan farklı olarak görülmektedir. "Nitel araştırma; insani deneyimler ve gerçeklikler hakkında geniş kapsamlı sorular yoluyla insanların yaşamlarını anlamamıza yardımcı olabilecek zengin ve betimleyici verilerin üretilmesi şeklinde tanımlanabilir" (Arastaman, Öztürk Fidan ve Fidan, 2018, s.42). Nitel araştırmaların güvenirlik ve geçerliği de bu tanım doğrultusunda araştırmanın tutarlığı, açıklığı, anlaşılabilirliği, aktarılabilirliği, inandırıcılı̆̆ı, uyumluluğu, vb. kavramlarla ifade edilmektedir (Merriamand Tisdell, 2016, s.239).

Bu yaklaşımlar doğrultusunda araştırmanın güvenirlik ve geçerliğini sağlamak amacıyla şu aşamalar uygulanmıştır: Araştırmanın inandırıcılığını sağlamak için araştırma öncesinde katılımcılar araştırmanın amacı ve içeriği konusunda bilgilendirilmiştir. Toplanan veriler katılımcılar tarafından teyit edildikten sonra veri işleme süreci başlatılmıştır. Araştırmacıların objektif olmaları yönünde dışardan bir uzman görüşüyle veriler üzerinden yapılan kod-kategori ve temaların uygunluğu test edilmiştir. Aktarılabilirliğinin sağlanması için araştırmanın amacına uygun olarak oluşturulan sorular net bir şekilde açıklanmış, çalışmanın nerde, nasıl yapıldı̆̆ı açıklayıcı bir şekilde sunulmuştur. Ayrıca katılımcıların görüşleri doğrudan alıntılarla bulgularda verilmiştir.

Araştırmanın güvenirliğini sağlamak amacıyla araştırmaya katılan bireylerin özellikleri ayrıntılı olarak tanımlanmıştır. Katılımcıların demografik bilgileri ayrıntılarıyla verilmiştir. Araştırma sürecinde elde edilen verilerin hangi katılımcılara ait olduğu aktarılmıştır. Araştırmanın dış güvenirliğini (teyit edilebilirliğini) sağlamak amacıyla kullanılacak olan yarı yapılandırılmış görüşme formu araştırma öncesinde ön uygulama ile test edilmiş ve sonrasında asıl uygulamaya hazır hale getirilmiştir. 


\section{Bulgular}

\section{Yöneticilerin teknoloji kullanımına yönelik tutumlarıla ilgili bulgular}

Okul yöneticilerine yönetimde teknoloji kullanımının ne anlama geldiği sorusu yöneltilmiş ve verilen cevaplar aşağıdaki tabloda verilmiştir.

Tablo 2.Yöneticilerin teknoloji kullanımına yönelik tutumlar

\begin{tabular}{l|l}
\hline Teknoloji sizin için ne anlama gelmektedir? & f \\
\hline Teknoloji vazgeçilmezdir. & 12 \\
\hline Teknoloji kolaylıktır. & 9 \\
\hline Teknoloji bir nimet. & 5 \\
\hline Teknoloji gelecektir. & 2 \\
\hline Bazen kolaylık, bazen sorun. & 2 \\
\hline Teknoloji zaman tasarrufudur. & 1 \\
\hline
\end{tabular}

Okul yöneticilerinin teknolojiyi tanımlama sözleri belirgin olarak teknolojiye karşı olumlu bir tutuma sahip olduklarını göstermektedir. Katılımcllardan 12 'si teknolojinin vazgeçilmez olduğu yönünde tanımlamalar yapmıştır. - Iç̧inde bulunulduğumuz çă̆ teknoloji çă̆ı. Her işimizi onunla yapıyoruz. Teknoloji olmadan yaşamak imkânsiz gibi (Y3).

- Benim için teknoloji demek yaşamm kendisi demek, aslında herkes için bu böyle artık. Teknolojisiz yaşamak artık imkansız gibi bir şey. Bu sadece bizim için değil, öğrencilerimiz için, velilerimiz için de böyle. Ev hanımı velilerimiz var, toplantrya telefonsuz gelmiyorlar, o kadar ki bağımlı olmuşlar. (Yrd 2)

Dokuz katılımc teknolojiyi kolaylık olarak anladığını ifade etmiştir. Geçmişte yapılan işlerin günümüzde teknoloji ile ne kadar kısa ve kolayca yapıldığına işaret eden katılımcılar aşağıdaki ifadeleri kullanmışlardır.

- Yillar önce mesleğe yeni başladı̆̆ımda her şey çok farklıydı. Bugünkü anlamda teknolojinin T'si yoktu. Tüm işleri elle yapardık. Fotokopi yok, bilgisayar yok, internetin hayali yok. Bu günkü saniyelik işleri yapmak için saatlerce çalışırdık, kalem kâğıt yazardık, çizerdik. Cetveller özel kalemler falan. Kimdi büyük kolaylı. Bunun değerini bilmek lazım. (Y1) 
- Bir yönetici olarak teknolojiden çok yararlantyoruz. Bize çok kolaylık sağlıyor. Teknoloji demek kolaylık demek. Örneğin bir duyuru yapmam gerektiğinde anında tüm öğretmenlerime whatsup üzerinden iletiyorum. (Y6)

Okul yöneticileri teknolojiyi kullanmaktan çok memnun gözükmekteler ve farklı ifadelerle belirtseler de teknolojinin çok gerekli, faydalı ve önemli bir araç olduğu hususunda bir anlaşma içinde oldukları görülmektedir. İki yönetici teknolojiyi gelecek olarak tanımlamışlardır.

- Teknoloji demek her şey demek, gelecek demek. Artık gelecekte her şey teknolojiye dayah olacak. Akıllı telefonlar, akıllı TV'ler, akıllı arabalar, akıllı evler... Gelecekte her şey akıllı olacak. Bu da herkesin daha çok teknolojiye bağhl kalacă̆ının işareti. Öyle değil mi? (Ydr3)

Teknolojinin olumlu yanları konusunda hemfikir olmalarına rağmen iki katılımcı teknolojinin aynı zamanda problem olduğunu ifade etmiştir. Teknolojinin çok hızlı değişmesini aynı zamanda bir sorun olarak görmekteler ve buna ilişkin bazı kaygılarının olduğu anlaşılmaktadır. Örneğin branşı Din Bilgisi ve Ahlak olan 29 yıllık bir öğretmen ve aynı zamanda yönetici olan bir katılımcı şunları söylemektedir:

- Teknoloji iyi, güzel de bunun sonu nereye varacak diye bazen kaygılaniyorum. Bir şey çıkıyor, onu tam anlayamadan başka yeni bir şey çıkıyor. Bazen kendimi eksik ve çaresiz hissediyorum. Bize göre değil bu kadar hızh değişim. (Yrd4)

Teknoloji bu kadar hızla gelişirken elbette herkesin aynı düzeyde buna uyum gösterebilmesini bekleyemeyiz. Bu hızlı değişime uyum sağlayabilmek için gerek bireysel gerekse örgütsel düzeyde bazı uyum ve gelişim çabalarının olması kaçınılmazdır.

\section{Yöneticilerin kendi algılarna göre teknolojik yeterlik düzeyleriyle ilgili bulgular}

Gerek günlük hayatımızda gerekse yönetimde teknoloji kullanımında en büyük sorun onu takip edebilme, kendimizi geliştirebilme ve yeterince teknolojiden yararlanabilme konusunda görülmektedir. Bu araştırmanın da alt problemlerinden birisi yöneticilerin teknoloji konusunda kendilerini ne düzeyde yeterli gördükleri hususudur. Bununla ilgili bulgular Tablo 3' de verilmiştir. 
Tablo 3.Yöneticilerin teknolojik yeterlilikleri

\begin{tabular}{ll}
\hline Teknoloji kullanımında ne kadar yeterli olduğunuzu düşünüyorsunuz? & $\mathbf{f}$ \\
\hline Kendi işlerimi yapabilecek kadar yeterliyim. & 8 \\
\hline Zaman zaman yetersiz kallyoruz. & 6 \\
\hline İyi durumda olan arkadaşlardan destek alıyoruz. & 3 \\
\hline İare ediyoruz ama teknik eğitim verilse daha iyi olur. & 3 \\
\hline Bu konuda kendimi yeterli görüyorum. & 2 \\
\hline
\end{tabular}

Tablo dikkatlice incelendiğinde yöneticilerin çoğunluğunun kendilerini tam olarak yeterli görmedikleri anlaşılıyor. Teknolojiyi izleyebilme, geliştirebilme ve tam manasiyla her alanda kullanabilme konusunda katılımciların farklı düşünceleri olduğu anlaşılmaktadır. Bir taraftan yeterli olduklarını belirtmekte öte yandan yetersiz kaldıklarını ifade ettikleri anlaşılıyor. Brançı sınıf ögretmenliği olan ve 23 yıllık hizmeti olduğu anlaşılan bir katılımcı durumu şöyle ifade etmiştir:

- Bu okulda sahip olduğumuz donanimlar eski. Ne kadar istesek de yenilikleri takip edemiyoruz. Bu kadar hızl değişime uyum sağlamak zor. Ekstra bir uzmanlık gerektiriyor. Bi çok alanda bilgisayar ve interneti kullanıyoruz ama artık sorunlarımız da artmaya başladı. Biraz bizlerin yetersizliği biraz kullandığımız teknoloji yetmediği için sorunlar çıkıyor haliyle. (Y2)

Katılımcların çoğu teknoloji kullanımı konusunda ileri düzeyde olmadıkların ima etseler de kendi işlerini halledebilecek kadar kendilerini yeterli hissetmekteler. Yöneticilerin teknoloji konusunda sorun yaşadıklarında genellikle bu konuda daha iyi durumda olan arkadaşlarından yardım aldıkları anlaşliyor.

- Genellikle kendi işimizi kendimiz yapıyoruz. Takıldığımız durumlar da olmuyor değil tabi. Öyle durumlarda da sağ olsun bazı arkadaşlar bu konularda çok daha iyiler. Onlara rica ediyoruz, yardım alıyoruz. Öğreniyoruz. Öğrenmenin yaşı yok. (Yrd1)

Katılımcılardan sadece ikisi teknoloji kullanımı konusunda kendilerini yeterli bulduğunu belirtmiştir. Bu konuda yeterli oldukları anlaşılan katılımc1ların ifadeleri de aslında çoğu yöneticinin bu konuda yeterli bilgi, beceri ve donanıma sahip olmadıklarını göstermektedir. Bu konuda çok net ifadeler kullanan bir katılımcı şunları söylemektedir: 
- Bazen düşünüyorum bu kadar iyi olmak işlerimi de artırıyor. Nedeni de çoğu öğretmenimizin ve hatta yöneticimizin bilgisayar ve interneti iyi kullanamamaları. Sürekli bir yerlerden çağrillyorsunuz. Yapmanı gereken işleriniz oluyor ama öte yandan insanlar sizden acil yardım bekliyor. Bazen başkalarnın yapması gereken işler de üzerime kalıyor. Bu bakımdan dedim yani. (Yrd2)

Katılımcıların ifadelerinden ve gözlemlerden ortaya çıkan bulgulara göre yöneticilerin çalıştıkları okul türüne göre bazı farklılıklar olduğu anlaşılmıştır. Katılımcların bazıları bilgisayar ve internet konusunda ve teknoloji kullanımı ile ilgili hizmetiçi eğitimler aldıkları anlaşılmıştır. Az sayıda da olsa bazı katılımcıların branşları veya özel ilgileri nedeniyle kendilerini daha iyi geliştirdikleri anlaşılmıştır. Bazı okullarda yöneticiler kendilerini daha avantajlı görmekteyken bazı okullarda ise donanım ve alt yapı eksikliği, teknoloji konusunda yeterli bilgiye ve deneyime sahip elemanların eksikliği nedeniyle teknolojiden etkili yararlanamadıkları bulgusuna varılmıştır.

\section{Okul yöneticilerinin yönetimde teknolojiyi kullanım alanlarnyla ilgili bulgular}

Araştırmanın ortaya koymayı hedeflediği alt problemlerden birisi de yöneticilerin teknolojiyi hangi alanlarda ve nasıl kullandıkları konusudur. Bu alt probleme ilişkin elde edilen bulgular genel olarak tüm yöneticilerin bazı alanlarda teknolojiyi rutin olarak kullandıklarını göstermektedir. Katılımcıların teknolojiyi hangi alanlarda kullandıklarını gösteren bulgular Tablo 4'te verilmiştir.

Tablo 4.Yöneticilerin teknolojiyi kullanım alanlar

\begin{tabular}{ll}
\hline Teknolojiyi hangi alanlarda kullanyorsunuz? & $\mathbf{f}$ \\
\hline Öğrenci işlerinde & 14 \\
\hline Personel işlerinde & 12 \\
\hline Büro işlerinde & 7 \\
\hline Planlama işlerinde & 6 \\
\hline Kütüphane işlerinde & 3 \\
\hline Sosyal kültürel etkinliklerin düzenlenmesinde & 3 \\
\hline letişim ve haberleşme gibi işlerde & 2 \\
\hline
\end{tabular}


Tabloya göre göre katılımcıların tamamı teknolojiyi öğrenci işlerinde kullandıklarını belirtmişlerdir. Katılımcıların tamamına yakını, 12 yönetici, teknolojiyi personel işlerinde kullandıklarını ifade etmişlerdir. Yedi katılımcı büro işlerinde teknoloji kullandıklarını belirtmiştir. Diğer kamu örgütlerinde olduğu gibi eğitim örgütlerinde de çoğu resmi işlem teknoloji aracılığıyla yapılmaktadır. Okular bakımından ele alındığında öğrenci hizmetleriyle ilgili işlemler, personel hizmetleri ve diğer bazı rutin resmi işlemlerin bu yolla yapılması zorunlu bir durum haline gelmiştir. Katılımcı ifadeleri ve elde edilen bulgular bilgisayar ve internetin eğitim örgütlerinde daha çok rutin resmi işlerin yapılmasında kullanıldığını göstermiştir.

- Teknolojiyi her yerde kullanıyoruz. Tüm öğrenci işerini, kayıtlardan tutun da öğrenci belgesi vermeye kadar her şey artık internetten yapilıyor. Duyurular yapıyoruz, velilerle iletişime geçiyoruz. Her yerde yararlanıyoruz aslinda. (Y5)

- Teknoloji demek bizim için bir nimet. Her şekilde kullaniyoruz. Eskiden manuel yaptığımız her şeyi şimdi internetten yapıyoruz. ... e-devlet sistemi çok önemli bizim için. Öğrenci işleri, personel işleri hemen hepsi artık bu şekilde yapılıyor. Teknoloji yöneticilerin işini çok kolaylaştırıyor. Iş̧leri daha hızlı ve doğru yapabiliyorsunuz bu şekilde. (Yrd3)

Teknolojinin öğrenci işlerinde, personel işerinde ve yazışma, dosyalama, gibi diğer resmi işlerde kullanımı konusunda katılımcılar benzer ifadeler kullanmışlardır. Bununla birlikte yönetimin en önemli süreçlerinden birisi kabul edilen planlama sürecinde teknolojiyi kullandıklarını belirten katılımcı sayısı altı olmuştur. Bilindiği gibi okullarımızda benimsenmiş olan yeni yönetim anlayışı stratejik plana dayalı bir anlayıştır. Stratejik planlama ve yönetim anlayışının temelinde ise çeşitli analizler, gerçekçi tespitler, planlamalar ve veriye dayalı doğru kararların alınması vardır. Tüm bu süreçlerde teknolojiden yararlanabilmek yöneticilere ve tüm çalışanlara önemli faydalar sağlar. Bu alanlarda teknolojinden yeterince yararlanılamaması yönetimsel bakımdan bir eksiklik olarak görülebilir. Benzer şekilde, kara verme, yöneltme, iş birliği ve değerlendirme / kontrol gibi yönetimsel süreçlere yönelik ifadelerin kullanılmadığı görülmüş̧tür. Yöneticilerin bu alanlarda teknolojiden yeterince yaralanmadıkları anlaşılmıştır. 


\section{Eğitim yönetiminde teknolojinin daha etkin kullanımıyla ilgili bulgular}

Yönetimde teknolojinin daha etin kullanılması için neler yapılabileceği sorusuna katılımcıların verdiği yanıtlardan elde edilen bulgular Tablo 5 'te verilmiştir.

Tablo 5.Yönetimde teknolojinin daha etkili kullanılması

\begin{tabular}{ll}
\hline Daha etkili kullanım için neler yapılmalı? & $\mathbf{f}$ \\
\hline Teknik donanımlar ve alt yapı yenilenmeli & 8 \\
\hline Alt yapı sorunu olan okullara yardım yapılmalı & 6 \\
\hline Hizmetiçi destek verilmeli & 5 \\
\hline Her okulda teknoloji tasarım öğretmeni olmalı & 2 \\
\hline Öğretmen yetiştirme programlarına teknoloji konusunda dersler konulmalı & 1 \\
\hline
\end{tabular}

Tablo 5'teki bulgular bize okullarımızın büyük ölçüde teknolojiyi temin etme, geliştirme ve etkin kullanma konusunda desteğe ihtiyacı olduğunu göstermektedir. Katılımcılardan sekizi okulların teknik donanım ve alt yapılarının yenilenmesini önermiştir.

- Teknoloji her geçen gün hızla gelişiyor. Uyum sağlamak kolay olmuyor. Elimizdeki malzemeler kısa sürede modası geçiyor. Yenilenmesi lazım, bu da maliyet demek. (Y3)

- En önemli sorunumuz alt yapı ve kullandığımız araçlarm eski ve yetersiz olması. Burası bir devlet okulu sonuçta. Her istediğiniz teknolojizi isteyince alamıyorsunuz. Biz de elimizden geldiğince sağdan soldan toparlayıp bir şeyler yapmaya çalışıyoruz. (Yrd6)

Devlet okullarında yönetici olan katılımcların hemen hepsi donanım ve alt yapı sorununa ilişkin sorunlardan bahsetmişlerdir. Okullara bu konuda yardım yapılmasını önermektedirler. Beş katılımcı teknoloji kullanımına ilişkin yöneticilere ve öğretmenlere hizmet içi eğitimler verilmesini önermişlerdir. Katılımcların çoğu teknoloji kullanımıyla doğrudan ya da dolaylı bir hizmetiçi eğitim programına katıldığını belirtmişlerdir. Ancak önceki dönemlerde katıldıkları bu program içeriklerinin yeni teknoloji ve uygulamaları kapsamadığı anlaşılmaktadır.

- Teknolojide her şey çok çabuk değişiyor. Daha önce ben de diğer birç̧ok yönetici arkadaş gibi kurslara katıldım, zaten zorunluydu bu kurslarm bazılarına 
katılmamı. Ancak yeni programlar ve uygulamalar oradaki öğrendiklerimizden çok farklı. (Y2)

Özel okulda görev yapan bir katılımcı ise teknolojinin yönetimde daha etkili kullanımına ilişkin öğretmen adaylarının hizmet öncesi eğitiminde bu konularda daha fazla ders alması gerektiğini önermiştir.

Araştırmada ortaya çıan önemli bir bulgu katılımcı yöneticilerin daha çok teknolojiyi eğitim ve öğretim, öğrenci işleri, personel işleri, haberleşme ve iletişim gibi alanlarda kullandıkları ve bu doğrultuda önerilerde bulundukları görülmektedir. Teknolojinin yönetim süreçlerinde kullanımı ve daha etkili hale getirme konusunda beklenen düzeyde görüş ortaya çıkmamıştır.

\section{Sonuç Tartışma ve Öneriler}

Okul yöneticileri günümüzde kendilerinden beklenen yönetim görevlerini yerine getirebilmek için teknolojiyi yeterince takip edebilmeli, kullanabilmeli ve okulun etkililiğini sağlamak için hem kendileri hem de birlikte çalıştıkları öğretmeler ve diğer görevliler teknolojinin tüm olanaklarından faydalanabilmelidir. Bu gereklilik okul yöneticilerinin birer eğitim lideri olmaları yanında ayrıca teknoloji liderliğini de zorunlu kılmaktadır. Günümüzde okullarda yürütülen her türlü faaliyette teknolojiden belirli düzeyde faydalanılması gerekmektedir. “Okul müdürleri ancak teknolojiyi bilen, kullanan ve benimseyen kişiler olarak liderlik rollerini yerine getirebilirler" (Banoğlu, 2011, s.200).

Bu araştırmada okul yöneticilerinin yönetimde teknoloji kullanımına yönelik görüşleri ortaya konulmaya çalışılmıştır. Araştırmaya katılan yöneticiler genellikle teknolojiye ve teknolojinin yönetimde kullanılmasına olumlu baktıkları anlaşılmıştır. Teknolojinin gerekliliğini kabul ettikleri sonucuna varilmıştır. Okul yöneticilerinin teknolojiye karşı olumlu tutumlara sahip oldukları yapılan diğer çalışmalarda da ortaya konmuştur ve bu çalışmada elde edilen sonuçlarla tutarlılık göstermektedir. Okul yöneticilerinin teknolojik yeterliliklerine ilişkin yapılan çalışmalarda yöneticilerin teknolojiyi okulda kullanmakta istekli olması, teknolojik yeterliliği okulun etkililiğini artıran bir durum olarak görmeleri, öğretmenlere ve öğrencilere teknolojiye erişim imkânı sağlanması gerektiği görüşünde olmaları, okul çalışanları ve öğrencileri için internete erişim olanakları sunmalı şeklinde ortaya çıkan literatür sonuçlarıyla benzerdir (Cantürk ve Aksu, 2017; Cantürk, 2017, s.33). Benzer bir 
çalı̧̧mada "ilköğretim okul yöneticilerinin bilgisayar teknolojisine karı tutumlarının olumlu olduğu tespit edilmiştir" (Günbayı ve Cantürk, 2011, s.65).

Bu araştırmada okul yöneticilerinin teknolojik yeterlilikleri, teknolojiyi temin etme, geliştirme ve etkili kullanma konusunda katılımcılara göre farklı sonuçlar elde edilmiştir. Konuyla ilgili yapılan diğer araştırmaların da farklı sonuçlar ortaya koyduğu görülmektedir. Okul müdürlerinin teknolojik liderliği, eğitimde teknoloji kullanımı ve konuya ilişkin yapılan diğer çalışmalar geçmişten günümüze doğru gelindikçe olumlu yönde bir farklılaşma olduğunu göstermektedir. Örneğin 2000'li yılların başında yapılan çalışmalar genellikle yönetici ve öğretmenlerin teknolojik yetersizliklerine ilişkin sonuçlar ortaya koymuştur (Karsl1, 2001; Turan, 2002; Özden, 2003; Yılmaz, 2005). Son on yılda yapılan araştırmalar ise genellikle yönetici ve öğretmenlerin teknolojik yeterliliklerinin orta ve üzeri düzeyde olduğunu göstermektedir (Haclfazlığlu, Karadeniz, ve Dalgıç, 2010; Banoğlu, 2011; Durnalı, 2018).

Yöneticilerin teknoloji liderliği yeterlilikleriyle ilgili yapılan çalışmalarda yöneticiler kendilerini ileri düzeyde yeterli görmekteyken öğretmenlerin algisına göre yöneticiler orta düzeyde yeterliliğe sahip olarak görülmektedir (Bülbül ve Çuhadar, 2012, s.487). Uğur ve Koç (2019, s.64) tarafından yakın zamanda yapılan bir araştırmada sonuçlarına göre bazı yöneticiler teknolojiyi okullarına sağlama ve kullanabilme konusunda kendilerini yeterli bulurken bazı yöneticiler birçok farklı etkene bağlı olarak bu konuda kendilerini yeterli bulmadıklarını, bu konudaki kendi rollerinin farkında olmadıklarını düşünmektedirler.

Banoğlu (2011, s.205) tarafından yapılan bir araştırmada ise okul müdürlerinin teknoloji liderliği üç boyut üzerinden araştırılmıştır. Araştırmada okul yöneticilerinin "liderlik ve vizyon" boyutunda teknoloji liderliği yeterliği en düşük değere sahipken, "öğrenme ve öğretim" boyutundaki yeterliği en yüksek değere sahiptir. "Ölçme ve değerlendirme" boyutunda teknoloji liderliği yeterliği ise orta düzey olarak bulunmuştur.

$\mathrm{Bu}$ araştırmada okul yöneticilerinin teknolojiyi daha çok öğrenci hizmetleri, personel hizmetleri, büro işleri gibi rutin ama kolaylaştırıcı ve zaman kazandırıcı işler için kullandıkları bulgusuna varılmıştır. Bu çerçevede ele alındığında yöneticiler aslında e-okul, mebsis, vb. yasal uygulamaların bir gereği olarak kullandıkları söylenebilir. Bilindiği gibi diğer kamu örgütlerinde olduğu gibi okullardaki rutin işler büyük ölçüde internet üzerinden yürütül- 
mektedir. Yönetimin işlevlerini yerine getirmesinde bu hizmetlerin de zamanında ve eksiksiz yürütülmesi önem arzeden bir durumdur. Örneğin ders programlarının kısa zamanda ve en rasyonel olarak yapılması, öğrencilerin devam durumunun ve notlarının uygun sürelerde sisteme girilmesi ve ilan edilmesi gibi yönetimi doğrudan ilgilendiren işlerin bilgisayarlar aracılığıyla etkili bir şekilde yürütülmesi olumlu bir durumdur. Bununla birlikte, yönetim amaca ulaşmaya yönelik yürütülen süreçler (planlama, karar verme, örgütleme, denetim vb.) olarak kabul edilir. Bu süreçlerin teknoloji aracllı̆̆ıyla daha iyi işletilmesi ve verimli hale getirilmesi bakımından, bu çalışmaya katılan yöneticilerin teknolojiyi etkin kullanamadıkları sonucuna ulaşılmıştır.

Alanyazında yapılan çalışmaların daha çok yöneticilerin teknoloji liderliği ve eğitimde teknoloji kullanımı ile ilgili olduğu görülmektedir. Yönetim süreçlerinde teknoloji kullanımına ilişkin bir çalışma Cantürk (2016) tarafından yapılmıştır. Çalışmada yöneticilerin yönetim süreçlerinde Bilgi İletişim Teknolojileri (BIT) kullanma durumları hem öğretmen hem de yönetici görüşlerine göre araştırılmıştır. Elde edilen sonuçlara göre, yönetim süreçlerinde BİT'in kullanımına ilişkin öğretmen ve yönetici görüşleri arasında anlamlı farklılıklar görülmüştür. Karar verme-planlama, örgütleme, eşgüdümleme, iletişim, etkileme ve değerlendirme boyutlarında yönetici görüşlerinin öğretmen görüşlerine göre daha yüksek olduğu belirlenmiştir. Yöneticiler yönetim süreçlerinde BİT'i yüksek oranda kullandıkları yönde görüş bildirirken, kendi okul yöneticilerini değerlendiren öğretmenlerin görüşleri daha düşük oranda çıkmıştır (Cantürk, 2016, 201). Ancak ilgili çalışmada ulaşılan sonuçlar incelendiğinde burada vurgulanan BIT kullanım alanlarının da büyük ölçüde öğrenci hizmetleri, devam devamsızlık durumunun takibi, öğretimde teknoloji kullanımı vb. olduğu anlaşılmaktadır (Cantürk, 2016, 202-205).

Yönetimde teknolojiyi daha etkin kullanabilmeleri için neler yapılabileceğine ilişkin olarak özetle şu sonuçlara ulaşılmıştır: Okulların alt yapı sorunları düzeltilmeli ve yeni donanımlar sağlanması gerektiği sonucuna varılmıştır. Yönetici ve öğretmenlere yönelik teknolojiyi etkin kullanabilme konusunda hizmet içi programların düzenlenmesi gerektiği anlaşılmıştır. Uğur ve Koç $(2019,64)$, tarafından yapılan bir çalışmada da benzer sonuçlara varılmıştır.

\section{Öneriler}

- Okul yöneticileri okulda teknolojinin yönetim süreçleri gibi alanlarda etkili kullanılabileceği konusunda bilgilendirilmelidir. 
- Yönetime ilişkin süreçlerde teknolojinin daha etkili kullanılmasına yönelik mesleki gelişim programları düzenlenmelidir.

- Okulların ihtiyaç duyduğu teknik donanımlar sağlanmalı ve alt yapı sorunları çözülmelidir.

- Öncelikli olarak teknik desteğe ihtiyaç duyulan okullara olmak üzere, tüm okullara bilişim teknolojileri branşında öğretmenler görevlendirilmelidir.

- Okul yöneticilerinin yönetimde teknolojiyi kullanabilme durumları yönetsel süreçler (planlama, karar verme, iş birliği ... gibi alt boyutları) üzerinden nicel ve nitel yöntemlerle araştırılmalıdır. 


\section{EXTENDED ABSTRACT}

\section{School Administrators' Opinions on the Use of Technology in Educational Administration \\ İhsan Topçu - Mustafa Ersoy \\ Sivas Cumhuriyet University}

The most important role for organizations to renew and improve themselves falls to their managers. This also applies to school administrators. Today, development and change are inevitable in all aspects of life and, like all organizations, educational institutions must make use of the highest technology, such as the Internet and computers. Computers, technologies and other developments in the field of telecommunications can be one of the key factors for the educational reforms to be undertaken in our country. It is believed that technology will play an important role in the restructuring of schools. Therefore, school principals who know how to exploit technology in management and apply it to managerial processes will be more privileged to create more effective schools.

Development and change are inevitable in every field of life and like all organizations, educational organizations have to benefit from the highest technology including mainly internet and computers. Computers, technological and other developments in the field of telecommunications may be one of the key factors for the educational reforms which will be realized in our country. It is hardly believed that technology will play an important role for the restructuring of the schools. For this reason, school principals who can apply technology to their managerial areas will be more privileged to create the more effective schools.

Turkey's 2023 education vision emphasizes data-based planning and management. One of the important issues highlighted in the vision document is to prioritize more effective use of technology in all areas of education and to highlight data-based management. In the frame of this plan, it is expressed that A Data Base Planning and Management System will be implemented on a school basis to monitor, evaluate and improve management and learning activities across the country. "Data from the ministry's existing systems will be integrated within an easily accessible Educational Data Warehouse. This 
includes data from MEBBIS, e-School, EBA, MEIS, DYS, e-Guidance, e-Extensive, Open Education Systems, e-Personnel, e-Registration, Book Selection, Optimum Staffing Processes, Physical Disability Inventory, e-Graduate, and Central Exam Results" (MEB, 2019).

For the innovation and renewal of organizations, the most important role is played by their managers and administrators. This is also true for school principals. This study aims to reveal the views of school principals about the use of technology for effective school management in educational institutions. Within the frame of the main problem of the research, answers to the following questions were sought:

1. What are the attitudes of the school administrators regarding the use of technology in educational administration?

2. What are the technological competence levels of the managers according to their perceptions?

3. How do school principals consider technology within the scope of their own duties and responsibilities?

4. How can they benefit enough from technology to make their administration more effective?

These are the basic questions of this study and the answers were tried to be found through the views of school principals.

Nowadays, the intensity of qualitative research in social sciences is increasing gradually. In this study, it has been preferred to use qualitative research method, as well. Phenomenology design was preferred in order to reveal the emotions, thoughts and knowledge of the school administrators in depth. Participants of the study were determined by purposeful sampling.

The population of this study were selected among the school principals employed in the schools (primary, secondary and high schools) in the centre of Sivas province. The participants consist of 14 school administrators, seven of whom are school principals and seven of them are assistant principals working in private and public schools in Sivas city center. The data of the study were collected by semi-structured interview forms developed by the researchers. The semi-structured form was given to the participants and they were asked to write their opinions related the subject. Obtained data were arranged as meaningful themes. Irrelevant data were neglected and relevant data found beneficial for the study questions were classified for the content analysis. They were coded, evaluated and prepared as a research report. 
The data of the research was analyzed by content analysis. It was understood that the participants had positive views on technology and the use of technology in management. In the research, different results were obtained in terms of technological competencies of school administrators and using technology in management. In the study, it was found that school administrators mostly use technology for routine but facilitating and time-saving tasks such as student services, personnel services and office work. When evaluated in terms of using technology in managerial processes, it was concluded that the managers participating in the study could not use the technology effectively.

Research results show that school principals have a positive attitude against technology usage in school management. About the need for technology usage in their administration, they all have similar opinions and ideas. Yet, on the point of having enough technological equipment in their schools, it was found that there were differences among schools depending on school types. Some principals believe that they are disadvantageous. As for having the skills and ability to use technology and to develop it for application to their administration, it was understood that they were at different levels.

\section{Kaynakça / References}

Afshari, M., Bakar, K. A., Su Luan, W., Abu Samah, B. Ve Fooi, F. S. (2009). Technology and school leadership.Technology,PedagogyandEducation, 18(2), 235-248.

Alpar, D., Batdal, G. ve Avcı, Y. (2007). Öğrenci merkezli eğitimde eğitim teknolojileri uygulamaları. Hasan Ali Yücel Ĕ̆itim Fakültesi Dergisi, 7(1), 9-31.

Arastaman, G., Öztürk Fidan, İ. ve Fdan, T. (2018). Nitel araştırmada geçerlik ve güvenirlik: kuramsal bir inceleme. YYü Eğitim Fakültesi Dergisi (YYU Journal of EducationFaculty), 15 (1), 37-75.

Banoğlu, K. (2011). Okul müdürlerinin teknolojik liderlik yeterlikleri ve teknoloji koordinatörlüğü. Kuram ve Uygulamada Eğitim Bilimleri, 11(1), 199-213.

Berber, Ö. (2017). Okul yöneticilerinin teknoloji okuryazarlı̆̆ının incelenmesi (Yayınlanmamıs yüksek lisans projesi). Trakya Üniversitesi Sosyal Bilimler Enstitüsü, Edirne.

Bogdan, R. andBiklen, S.K. (2006). QualitativeResearchforEducation: An IntroductiontoTheoryandMethods. (5 ${ }^{\text {th }}$ Ed.). Pearson. 
Bowden, J.A. andWalsh, E. (Eds.). (2000). Phenomenography. Melbourne: RMIT UniversityPress.

Bostanc, H. (2010). Okul yöneticilerinin teknolojik liderlik yeterlilikleri açısından incelenmesi. Yayınlanmamış yüksek lisans tezi. Gazi Üniversitesi Bilişim Enstitüsü, Ankara.

Bülbül, T. ve Çuhadar, C. (2012). Okul yöneticilerinin teknolojik liderlik öz yeterlik algıları ve iletişim teknolojilerine yönelik kabulleri arasındaki ilişkinin incelenmesi. Mehmet Akif Ersoy Üniversitesi Ĕ̆itim Fakültesi Dergisi, 12(23), 474-499.

Cantürk ve Aksu, (2017).Okul yöneticilerinin teknolojik liderlik davranışları. Ĕğitim ve Öğretim Araştırmaları Dergisi, 6(4), 21-38.

Cantürk, G. (2016). Okul yöneticilerinin teknolojik liderlik davranışları ve bilişim teknolojilerinin yönetim süreçlerinde kullanımı arasındaki ilişki. Yayımlanmamış doktora tezi, Akdeniz Üniversitesi Eğitim Bilimleri Enstitüsü, Antalya.

Cantürk, G. (2017).Okul yöneticilerinin teknolojik liderlik davranışları. Ĕ̆itim ve Öğretim Araştırmaları Dergisi, 6(4), 21-38.

Chandra, Y. ve Shang, L. (2019). Qualitative research using R: A systematic approach.Springer.

Costa, A.P., Reis, L.P. ve Moreira, A. (Eds.) (2019). Computer Supported QualitativeResearch. Springer.

Creswell, J. W. (2016). 30 essential skills for the qualitative researcher. SAGE Publications, Inc.

Creswell, J. W. (2012). Educational research: Planning, conducting, andevaluatingquantitativeandqualitativeresearch (4th ed.) Pearson.

Creswell, J. W. (2009). Researchdesign: Qualitative, quantitative, and mixed methods approaches ( $3^{\text {rd }}$ Ed.). SAGE Publications, Inc.

Çalık, T., Çoban, Ö. ve Özdemir, N. (2019). Okul yöneticilerinin teknolojik liderlik öz yeterlikleri ve kişilik özellikleri arasındaki ilişkinin incelenmesi. $A n-$ kara Üniversitesi Eğitim Bilimleri Fakültesi Dergisi, 52(1), 83-106.

Durnalı, M. (2018). Öğretmenlere göre okul müdürlerinin teknolojik liderlik davranışları ve bilgi yönetimini gerçekleştirme düzeyleri. Yayımlanmamış doktora tezi, Hacettepe Üniversitesi, Eğitim Bilimleri Enstitüsü, Ankara.

Erbakırcı, M. A. (2008). Ankara ili ortaöğretim okul yöneticilerinin teknolojiye karşı tutumları ve yönetim bilişim sistemlerini kullanma durumları.Yayınlanmamış Yüksek Lisans Tezi, Ankara Üniversitesi Eğitim Bilimleri Enstitüsü, Ankara. 
Flanagan, L., ve Jacobsen, M. (2003). Technology leadership for the twenty-firstcentury principal. Journal of Educational Administration, 41(2), 124-142.

Flick, U. (2009). An introduction to qualitative research (4th Ed.). SAGE Publications, Inc.

Günbayı, İ. ve Cantürk, G. (2011). Bilgisayar teknolojisinin okul yönetiminde kullanımında okul yöneticilerinin bilgisayar teknolojisine karşı tutumları. Ordu Üniversitesi Sosyal Bilimler Enstitüsü Sosyal Bilimler Araştırmaları Dergisi, 2 (3), 47-70.

Hacıfazlığlu, Ö., Karadeniz, Ş. ve Dalgıç, G. (2010). Eğitim yöneticileri teknoloji liderliği standartlarına ilişkin öğretmen, yönetici ve denetmenlerin görüşleri. Kuram ve Uygulamada Eğitim Yönetimi, 16(4), 537-577.

Hai-Jew, S. (2015). Enhancing qualitative and mixed methods research with technology. IGI Global.

İşman, A. (2014). Teknolojinin felsefi temelleri. Sakarya Üniversitesi Ĕ̆itim Fakültesi Dergisi, 1.

Karslı, M. D., Gündüz, H. B., Titrek, O. ve Hamedoğlu, M. A. (2002).Eğitim yöneticileri ve öğretmenlerin bilişim teknolojilerini kullanma düzeyleri ve bilişim teknolojilerinden yararlanmalarını engelleyen nedenler.Sakarya Üniversitesi Ĕ̆itim Fakültesi Dergisi, 4, 176-188.

Lapan, S.D. Marylynn T. Quartaroli, M.T. ve Riemer, F.C. (Eds.) (2012). Qualitative research: An introduction to methods and designs. John Wiley\&Sons, Inc.

MEB (2018). MEB 2019-2023 strateji belgesi, MEB Strateji Geliştirme Başkanlı̆̆ı, Ankara.

MEB (2019) 2023 vizyonu. 17.10.2019 tarihinde http://2023vizyonu.meb.gov.tr/ adresinden erişilmiştir.

Merriam, S. B. (2009). Qualitative research: A Guide to design and implementation. Revised and expanded from qualitative research and case study applications in education. John Wiley\&Sons, Inc.

Merriam, S. B. and Tisdell, E. J. (2016). Qualitative research: A Guide to design and implementation. (4th Ed.). John Wiley\&Sons, Inc.

Özden, M. Y. (2003). Teknoloji ve eğitim: Ülke deneyimleri ve Türkiye için dersler. III. Türkiye'de İnternet Kullanımı Sempozyumu.

Patton, M. Q. (2015) QualitativeresearchEevaluationmethods: Integratingtheoryandpractice (Fourthedition). SAGE Publications, Inc.

Sayracı, N. ve Gündüz, H. B. (2018).Okul yöneticilerinin değişimi yönetme yeterlilikleri ve teknolojik liderliği.YILDIZ Journal of EducationalResearch, 3 (1), 27-61. 
Seay, D. A. (2004). A study of thetechnology leadership of Texas high school principals. (Unpublished doctoral dissertation), University of North Texas, Texas.

Sincar, M. ve Aslan, B. (2011). Elementaryteachers' viewsaboutschooladministrators' technology leadership roles. Gaziantep UniversityJournal of Social Sciences, 10(1), 571-595.

Silverman, D. (2006). Interpreting qualitative data. London: Sage.

Starks, H., and Trinidad, S. B. (2007). Choose your method: A comparison of phenomenology, discourse analysis, and grounded theory. QualitativeHealthResearch, 17 (10), 1372-1380.

Turan, S. (2002). Teknolojinin okul yönetiminde etkin kullanımında eğitim yöneticisinin rolü. Kuram ve Uygulamada Ĕ̆itim Yönetimi, 30, 271-274.

Uğur, N. G. ve Koç, T. (2019). Leading and teaching with technology: School principals' perspective. International Journal of EducationalLeadershipand Management, 7(1), 42-71.

Yıldız, İ ve İşcan, Ö. F. (2013). Bilgi teknolojilerinin kullanımı ve yönetsel karar verme tarzları ilişkisi: TOBB genç girişimciler kurulu (Doğu Anadolu Bölgesi) üyeleri üzerinde bir uygulama. Atatürk Üniversitesi İktisadi ve İdari Bilimler Dergisi, 27(3), 21-39.

Yılmaz, A. (2005). Eğitim yönetiminde bilgisayarlardan faydalanmanın avantajları ve dezavantajları. Milli Eğitim Dergisi,166, 72-81.

Yin, R. (2016). Qualitative research from start to finish (2nd Ed.). New York: The Guilford Press.

\section{Kaynakça Bilgisi / Citation Information}

Topçu, İ. ve Ersoy, M. (2020). Eğitim yönetiminde teknoloji kullanımına ilişkin okul yöneticilerinin görüşleri. OPUS-Uluslararası Toplum Araştırmaları Dergisi, 15(10. Y1l Özel Sayıs1), 4930-4955. DOI: 10.26466/opus.652611 